\title{
Green Architecture and Sustainability in the Complex Transformation of the Built Urban Environment in Jordan
}

\author{
Zaid A. O. Aldeek \\ Department of Architecture, Hijjawi Faculty for Engineering Technology, Yarmouk University, Jordan
}

Corresponding Author Email: zaid.d@yu.edu.jo

https://doi.org/10.18280/ijdne.150115

Received: 12 June 2019

Accepted: 5 November 2019

\section{Keywords:}

sustainable architecture, underdeveloped cities, affordability in green design, new thinking logarithms, new resources availability, parametric sustainability

\begin{abstract}
The complexity of green and sustainable transformation processes in the urban and architectural reality of Jordanian cities is increased by the effects of inappropriate building material use and inadequate design processes. This paper focuses on the difficulty of introducing sensible building proposals in underdeveloped contexts, caused by the inadequate definition of technical requirements for building performance. The aim of this paper is to provide innovative means to modify the parameters and practices of related projects, highlighting the concept of affordability as crucial in sustainable design processes and related technical choices in underdeveloped environments. The methodology adopted in this paper is based on theories that promote innovative visions, approaches, and concepts regarding the availability of building materials and energy resources. This paper introduces dynamism into sustainable architectural and urban regeneration, firstly make them more integrated to minimize waste, and through design processes that reduce environmental impact during renovating of existing buildings introducing recycling plans. Other outcomes of this paper include the use of affordable green and sustainable architectural parameters and the introduction of active proposals to simplify the complexity of the unbalanced relationship between affordability and sustainability in building design.
\end{abstract}

\section{INTRODUCTION}

Elements that increase the complexity of sustainable transformation in renovation practices in underdeveloped contexts, such as in Jordan, relate to many factors, including the gradual loss of local building traditions and the rapid urbanization that has produced thousands of inadequate buildings that must be renovated or demolished. This paper proposes that green and sustainable policies can make a valid contribution to the management of renovation processes and the development of technical interventions that improve sustainability, especially regarding affordable housing.

Affordability and green housing have various definitions and many contradictions. Whereas the main aim of affordable housing is cost reduction, while maintaining quality and standards, the second is to improve the quality of life in houses and urban spaces, which comes with additional costs. Usually, in green housing, advanced materials and solutions are necessary, which increases costs; thus, research regarding affordability in green housing presents challenges and requires further investigation.

Affordability is an important feature of housing and associated facilities relative to customers' ability to purchase houses. Affordability strategies seek to provide affordable accommodation for every family, at reasonable prices and with high quality. Affordability benefits low-income households who cannot acquire suitable accommodation without assistance; therefore, affordable housing helps low- and middle-income families to acquire appropriate housing without imposing financial hardship. There are several measures of housing affordability, including the price-income ratio, whereby affordability is measured as the relationship between a family's income and expenditure.

Designing affordable and sustainable houses requires new definitions and concepts of sustainability, involving the introduction of affordable green design standards and interventions that can modify current building methods with a green vision and supply new means of sustainability [1]. The purpose of this paper is to present and highlight best practice applications in green architecture design, focusing on issues, concepts, and micro solutions relating to macro problems. These factors are based on the appropriate use and natural application of physical principles to achieve comfortable conditions in affordable houses, highlighting the role of control of these elements, which may be smart, traditional, or a combination of both.

It is not easy being green in the housing sector, due to the generally elevated costs and the need to balance long-term benefits and costs. This highlights the difficulty that lowincome households face in supporting the costs of the hightech choices and materials-which are integral to current sustainability measures. To access smart solutions for resolving the problem of costs in sustainable design processes, we must develop a new concept of available materials recycling building construction waste.

Theoretically, green buildings do not require complex operation or costly mechanisms, and their benefits are not only environmental, but also economic and social - the long-term operating costs are reduced by rationalizing energy and water consumption, reducing emissions, maintaining adequate temperatures, and reducing waste. Avoiding the use of scarce natural resources, such as water, and selecting recycled 
resources can reduce construction costs [2]. Practical difficulties are inherent in the design process because the conservation of resources is not seen as priority when dealing with affordable housing in underdeveloped contexts.

Principally, green architecture advocates sustainable energy choices and the safe use of building materials and considers the environmental impact of site choices. Green architecture's definition is different in developed and underdeveloped countries, with the discrepancy being caused by unequal access to technology, since developed countries are characterized by their use of high-tech materials and advanced production processes.

Underdeveloped countries are under pressure to evolve rapidly, which blind them to any possibility of integrated policies that include good building performance in the design process [3]. It is necessary to find new affordable techniques to reduce the costs of building which means that building design should not only incorporate aesthetic values, but also practices that manage and reduce waste in the building process focusing on natural cooling and heating with the use of passive architectural methods, balancing conventional building consumptions with innovative renewable energy applications [4].

\section{METHODOLOGY}

Based on international cases in micro-collection of alternative energy and on lecturer review, this study formulated hypotheses that described the issue (affordable, green, and sustainable housing) with the finality to produce guidelines that permit the reduction of energy consumption in low-cost housing. The availability of materials is the determining factor in the success of these hypotheses, thus, we discussed new concepts of material availability and how these materials could be sustainable building materials, particularly, using low-cost materials through the use sustainable parametric potentiality (SPP).

Drawing on the results of studies relating to Jordanian buildings, specifically in the case of Irbid city regeneration projects [5], this study noted the impossibility of introducing elements of sustainability and green architecture on a large scale using conventional methods. The urban and architectural reality in Jordan is lacking to appropriate strategies that favor the urban sustainable development. It needs, firstly, interventions that introduce new methods of producing green urban spaces; secondly, re-design the internal spaces of buildings during renovation work focusing on the role of infrastructures in a sustainable development; and finally, employing appropriate techniques and building materials in these interventions. This paper concentrates on new ways of thinking that combine the above elements, proposing a strategy for dealing with sustainable transformation processes.

The principal element in our case study is rapid urbanization, which involves many factors that result in buildings that fail to meet appropriate standards and technical requirements. As a result, many buildings must be demolished, leading to abnormally large quantities of waste building materials that could recycled (see Figure 1).

However, Jordan lacks sources of aggregates and suffers from the negative effects of the aggregates industry in many ways-in terms of health, safety and the environment (see Figure 2). This research highlights sensible positive economic benefits coming out from developing strategies based on building waste recycling.

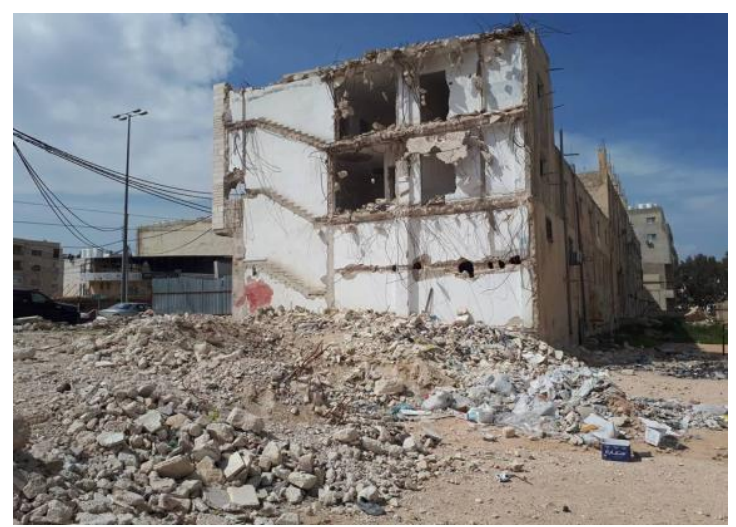

Figure 1. The demolishing of some buildings in Irbid City during requalification process. (Source: Author, 2019)

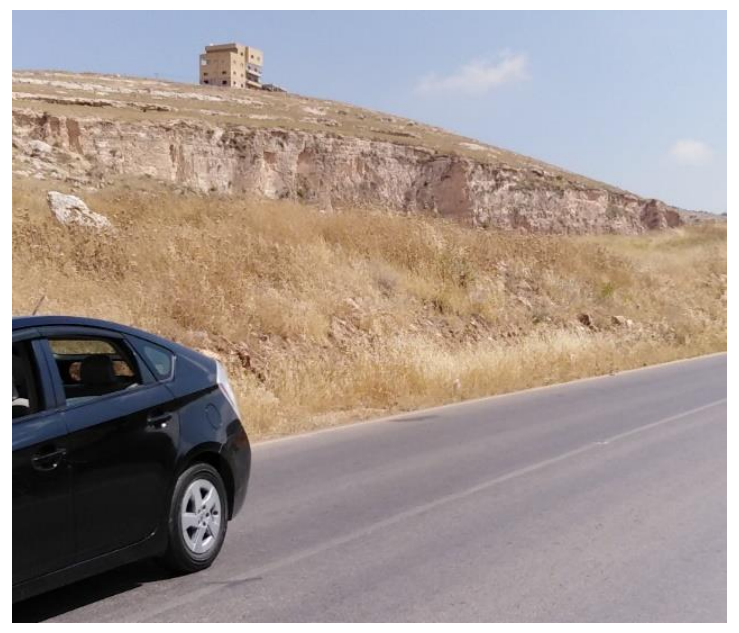

Figure 2. Example of the negative effects on air pollution, environment and security produced by the aggregate industries in Jordan. (Source: Author, 2019)

\section{LITERATURE REVIEW}

Retrofitting the existing unsustainable built environments created during rapid urbanizations is a global issue, not only in underdeveloped countries, and present an important design challenge. Many authors as Lukez [6] studied reasons and factors that determined this situation and how to reverse the situation, proposing, the "adaptive design process" in order to transform poorly designed suburbs into more suitable. The adaptive design process proposed by Lukez puts in evidence that design process must produce solutions that act on costs and affordability of interventions to be largely adopted.

Sustainable parametric potentiality (SPP) is an adaptive system of micro interventions in a design process with finality to produce large and attended effects. This is especially true for comfort conditions, acting on building materials and on how to employ them in the better way, in the initial phases of design. Correcting them in the late design stages often is expensive, if possible, so analyzing and predicting comfort conditions during the early design process through definition of materials and techniques employed [7].

The relationship between architectural design, the urban built environment, and sustainable choices has historic origins; for example, Greek architects designed their cities and houses 
according to criteria that allowed good ventilation and sun exposure for both urban morphology and the interiors of buildings [8]. They used grid patterns to plan the streets, which were oriented east-west, while the dwelling units were oriented in a north-south direction; thus, they were able to benefit from solar energy in the winter while, in the summer, the houses were partially shaded. Other examples include Arab and Muslim architecture, the design of which contains evidence of research into better agglomeration patterns, both vertically and horizontally, relating to the microclimate, as well as the use of grid patterns that permitted cities, urban spaces, and buildings to benefit from natural conditions [9].

The urban planning of Arab cities affords an important example of the application of the principles of green architecture through their compact forms and effective circulation paths in terms of width, length, shape, and orientation, wherein the compact design led to the mitigation of harsh climate effects, such as high temperatures and direct solar radiation, and the circulation paths were narrow and shaded to improve ventilation. Designs in extreme conditions, such as desert zones where intense sun exposure elevates temperatures and reduces humidity, have prompted designers to apply many theories and scientific techniques to address the issue of human comfort [10].

This paper focuses on proposing new methods of interpreting traditional elements of sustainability in local architecture. Passive techniques were generally used in vernacular buildings in Jordan-for example, thick walls and roofs to reduce heat radiation; wind catchers to improve ventilation; high, tiny windows; and interior courtyards for houses, often surrounded by plants and trees to increase humidity. Other traditional ways to achieve thermal comfort in vernacular buildings included Mashrabiyah (wooden lattice screens), the most effective orientation of buildings in relation to the climatic conditions, sheltering devices to create shade and shadow, and designs wherein small openings reduced exposure to strong sunlight. In addition, the compact urban form, especially in villages, decreased the direct sunlight in summer and heat loss in winter [11].

\section{DISCUSSION}

Many variables affect the achievement of affordable housing value in relation to household income as: the safety environment, the accessibility to public transport services, the use of schools and education centers, shopping, health and childcare, the absence of leisure services as green public spaces and housing quality in meanings of energy efficiency, elements not guaranteed in affordable housing generally. Energy efficiency in green affordable housing is one of the most important themes that must be taken into consideration highlighting the importance of waste recovery and energy management in buildings. Energy consumption in dwellings constituting a significant proportion of the overall energy consumption (20-40\%), making it an important factor to consider when analyzing energy-saving strategies [12].

Throughout the integrated design process for green building, architects and engineers rely on research to make design decisions that reduce energy wastage, using building simulations that illustrate how the building will react to the environment and how design parameters will affect the building's energy consumption. Some traditional geometric exploration tools assist architects in their evaluations, while simulation programs help in measuring building performance. Green architecture can improve building performance, and the practice of green construction has progressed, largely because of the development of integrated techniques across many engineering disciplines. Decisions regarding green design techniques depend on minimizing the designs' environmental impact over the buildings' lifecycle and considering how design standards affect energy consumption in the internal environment before actual decisions are made [13]. Green architecture using different design techniques and multitude of disciplines produces methods able to reduce energy consumption and increase the quality of the indoor environment.

Analyzing the common elements in traditional architecture in different geographic and cultural zones, we noted the use of available local resources and materials, the multiple uses of building materials in the same building, and the multiple uses of construction techniques that were generally applied in both vertical and horizontal sections [14]. The protection and good performance of buildings were also guaranteed by the urban form-in the desert, compact and enclosed houses with grand courtyards, providing an ideal urban design for all weathers and protection against heat, cold, wind, and direct solar exposure [15]. A comparative analysis between traditional and current methods of building in Jordan highlights the capacity of traditional methods of building to manage energy consumption using resources and materials in appropriate ways [16].

The primary cause of climate change is global warming, due to carbon dioxide emissions, which is one of the biggest threats of the twenty-first century. The latest studies have indicated that developing countries, which are considered to be the greatest energy-consuming countries, affect global warming, and consequently climate change, due to heavy manufacturing, rapid urbanization, and population explosion; hence the great need to reduce gas emissions through the adoption of building practices that use renewable resources-power generation using wind turbines, solar panels, and rainwater harvesting [17].

The zero-energy concept, in buildings, has received international attention in recent years and is now a common future target, with technology providing innovative and advanced solutions that reinterpret traditional principles using high performance materials and innovative design processes.

Designers must consider the great impact that the construction industry has on the environment. We will discuss later how this issue can be dealt with by focusing on the use of the recycled building materials (see Table 1). Sustainable building materials are characterized by several features, such as low energy consumption in transportation (of passengers from nearby areas), low energy consumption in manufacturing, and the use of fully recyclable materials (raw materials that have not been exposed to industrial processes that would prevent recycling of the material itself). Sustainable parametric potentiality (SPP) of a certain building material is given, generally, from the relationship between performance and costs, we assigned in our case values of the principal elements that contribute to define its performance to each building material with the finality to have a numerical definition of the (SPP). The numerical value expresses the potentiality of a building material to be considered sustainable. This potentiality is given analyzing principal factors, as shown in Table 1, presenting a dynamic concept of evaluation. The availability of a certain material plays an important role for example the rock as a building material has a high 
performance but in drastic reduction of availability thus, we can consider it as low parametric potentiality. On the other hand, plastic derivatives present a high availability such, we can consider them, with appropriate transformations, as high parametric potentiality.
Parametric design gives the possibility to have different vision when we affront a specific issue and can be considered a current trend in architectural design, particularly when applying concepts as the use of natural and recycled resources in underdeveloped contexts.

Table 1. Parametric elements of sustainable building materials (SPP) related to their performances. (Based on Elaboration and Tests by Author, 2019)

\begin{tabular}{ccccccc}
\hline Building Material & Availability & $\begin{array}{c}\text { Easy to be used } \\
\text { with Local } \\
\text { Technologies }\end{array}$ & $\begin{array}{c}\text { Chemical } \\
\text { Stability, Healthy } \\
\text { and Naturality }\end{array}$ & Durability & $\begin{array}{c}\text { Elevated } \\
\text { Thermal } \\
\text { Preservation }\end{array}$ & $\begin{array}{c}\text { Sustainable Parametric } \\
\text { Potentiality (SPP) }\end{array}$ \\
\hline Rock & $4 / 10$ & $6 / 10$ & $8 / 10$ & $8 / 10$ & $7 / 10$ & $6.6 / 10$ \\
\hline Enforced cement & $5 / 10$ & $6 / 10$ & $6 / 10$ & $5 / 10$ & $5 / 10$ & $5.4 / 10$ \\
\hline Raw clay & $9 / 10$ & $7 / 10$ & $7 / 10$ & $7 / 10$ & $9 / 10$ & $7.8 / 10$ \\
\hline Clay & $9 / 10$ & $8 / 10$ & $10 / 10$ & $9 / 10$ & $10 / 10$ & $9.4 / 10$ \\
\hline Expanded clay & $10 / 10$ & $8 / 10$ & $9 / 10$ & $10 / 10$ & $10 / 10$ & $9.4 / 10$ \\
\hline Light cement blocks & $8 / 10$ & $8 / 10$ & $6 / 10$ & $6 / 10$ & $6 / 10$ & $6.8 / 10$ \\
\hline Light aggregates & $4 / 10$ & $5 / 10$ & $5 / 10$ & $5 / 10$ & $6 / 10$ & $5 / 10$ \\
\hline Organic materials & $6 / 10$ & $8 / 10$ & $4 / 10$ & $4 / 10$ & $5 / 10$ & $5.4 / 10$ \\
\hline Plastic derivates & $10 / 10$ & $9 / 10$ & $7 / 10$ & $9 / 10$ & $7 / 10$ & $8.4 / 10$ \\
\hline
\end{tabular}

Design involving green architectural parameters means comprehending the natural environment and applying that understanding to sustainable design parameters-first, by reducing the consumption of traditional resources and, second, by using green design concepts such as orientation, performance of materials, and urban form. Table 2 shows sustainable design parameters (SDP) to take into consideration beside the cited below parameters of sustainable potentiality of building materials (SPP).

Table 2. Schematic interaction between sustainable design parameters (SPP) and minimal requirements of design parameters. Elaboration: Author 2019

\begin{tabular}{ccccc}
\hline $\begin{array}{c}\text { Sustainable Design } \\
\text { Parameters }\end{array}$ & Healthy Environment & Energy Efficiency & Sustainable Materials & $\begin{array}{c}\text { Morphology and Appropriate } \\
\text { Design }\end{array}$ \\
\hline & $\begin{array}{c}\text { Building materials and } \\
\text { systems used do } \\
\text { not produce elements of } \\
\text { toxicity. }\end{array}$ & $\begin{array}{c}\text { Ensure that the building's } \\
\text { use of energy is } \\
\text { minimized. }\end{array}$ & $\begin{array}{c}\text { Building materials } \\
\text { should be from } \\
\text { multiple sources. }\end{array}$ & $\begin{array}{c}\text { The building form should } \\
\text { respond to the site, region, } \\
\text { climate, and available materials. }\end{array}$ \\
\cline { 2 - 5 } & $\begin{array}{c}\text { Building materials } \\
\text { permit the design of } \\
\text { healthy internal areas. }\end{array}$ & $\begin{array}{c}\text { Buildings designed with } \\
\text { energy consumption } \\
\text { being minimal. }\end{array}$ & Safety of production. & $\begin{array}{c}\text { Integration and harmony between } \\
\text { users and the environment. }\end{array}$ \\
\hline
\end{tabular}

The elements that characterize this type of architecture relate to the use of various forms, technologies, and innovative materials for construction. Green architecture is based on the controlled use of resources to obtain the best results and create comfortable dwellings.

\section{RESEARCH KEY FINDINGS}

Sustainable architecture is complex, generally, difficulties are amplified when dealing with regeneration in underdeveloped cities. Sustainable parametric potentiality (SPP) can optimize many aspects because simplify processes. As, for example, Building Information Modelling (BIM) is a collaborative process with finality to integrate and to optimize complex issues information in a digital 3D model [18]. Sustainable parametric potentiality (SPP) confronts multiple problems and issues, these elements seem with minimized importance in first impact but crucial during the building evolution. By using the sustainable parametric potentiality, we can produce a matrix model of evaluation of choices to be adopted. This matrix defines materials, required performances and strategies of sustainability of design process.

One factor of complexity of applying sustainable choices is represented from the fact that the economic balance is a long- term investment. Another is the fragmented access to advanced technology results in an inability of the local building industry to stay abreast of developments. The limited economic resources pose many challenges regarding the sustainable design development. These three elements cited below motivate the research of affordability in green and sustainable design.

We can summarize as the first key finding of this paper is the need to organize green and sustainable transformation during the regeneration process using available building techniques, and to modify the design process to incorporate new thinking methods.

The second key finding is the need to manage the limited local resources using the sustainable parametric potentiality as instrument of appropriate resources employed during the transformation process through low energy transformations, recycling of waste building materials, and the introduction of a combination of these interventions.

\section{PROPOSALS AND OUT COMES}

This paper highlights that green and sustainable regeneration of urban buildings in underdeveloped contexts requires different approaches, since many factors play a 
crucial role solution must consider this difference in developing a technology that can be widely used and correspond to social and technical parameters. It must also be simple to execute, comprehensible to local operators, and use locally available materials. The selected technology should also be appropriate for use in different types of buildings. A fundamental requirement of the proposed technology is that it should offer a prototype characterized by flexibility, affordability, and diffusion potential.

\subsection{Techniques using low-energy consumption}

This section discusses alternative techniques based on different methods of using clay. The performance and quality of buildings that use clay, whether pure or mixed with other materials, offers a promising building methodology, characterized by adaptation to regional variations and responsiveness to different climatic conditions. The use of clay in many cultures and in different historical periods permits us to formulate a hypothesis regarding its use as a modern and affordable building material in underdeveloped countries. Ecological and economic imperatives in underdeveloped countries necessitate a return to using traditional resources, but in new ways.

Clay is a local material that is present in all parts of Jordan and is an affordable, non-toxic, recyclable, energy-efficient building material. Recent studies have focused on local raw clay as a potential green building material in Jordan, which is a country rich in different types of clay that may have industrial potential. The most common deposits are of kaolinite, bentonite, and black mud, which are widely distributed in Jordan [19].

The flexibility and performance of clay permits its consideration as a modern building material. In addition to its classical uses, light clay (liquid clay mixed with quantities of other materials such as aggregates) is a very good insulating material. Innovative building methods are associated with the so-called expanded clay having properties that permit many technical issues to be resolved with simple processes. In this paper, we focus on the consideration of clay as a modern building material that permits the creation of high-quality dwellings. However, considering only the performance of building materials, without a modern vision of habitation, will restrict the research to the radical reinterpretation of traditional techniques, taking as an example the construction of the village of Qarna by Fathy [9]. The construction at Qarna offered good technical experience but was unproductive as a model of green and sustainable architecture that could be expanded, due to the inadequacy of modern human interpretations.

Although clay is a widely available local material in Jordan, its use in buildings is marginal, being limited to decoration or building accessories despite its excellent performance on many levels. In this paper, we focus on means of using it that do not require a high consumption of energy.

Clay is a natural material formed by the disintegration of various types of rock. When mixed with water, it becomes plastic and malleable, and it can be used raw or subjected to thermal baking processes. Raw clay has always been used as a building material, since it requires minimal amounts of energy and simple processing techniques, and it is still used in territories that are technologically poor, where it is the only resource. Since ancient times, buildings have been built with clay both in the form of raw bricks (adobe) and molded, mixed, and pressed clay (pisé), combined with straw to reduce shrinkage. Clay is, in fact, a humidity regulator, since it can absorb the excess moisture in the air quickly and release it again when it is lacking, and it can absorb odors and smoke, contributing to healthy houses. It possesses remarkable capabilities regarding heating, the accumulation of heat, and cooling over a long time period. Due to its thermal inertia, clay manages to keep internal temperatures almost constant, so they are less affected by external temperature changes.

In this section, we focus on the use of clay in parts of buildings, to increase insulation and reduce energy waste by acclimatizing houses. Clay can be green and sustainable for low-income houses, in many ways:

\subsubsection{Simple use as a low-cost insulating building material}

A simple use of clay involves its insertion between the internal and external walls of façades, in its natural state, mixed with water, or simply compressed. The proposed process is a very simple method that can be implemented without specific technical requirements. This simplicity offers the potential for widespread diffusion because it does not require any energy consumption or specific operations, resulting in reduced cost of materials and optimization of the thermal integrity of external walls.

\subsubsection{Semi-worked and worked sections cooked in solar clay} ovens

The use of solar drying can easily be adopted to create worked and semi-worked blocks of clay, leading many researchers to hypothesize its extensive employment in different production sectors [20].

\subsection{Building materials based on the use of recycled waste}

In Jordan, the aggregates industry is poorly organized in many respects. Aggregate resources are divided into three types, the first of which involves the granulation of rocks, destroying large part of Jordan's hills and having a negative impact on the environment [21].

The second source is recycling, which derives from simple processes used by small and medium communities with low technology levels. These processes could easily be modified to produce alternative resources from the waste generated by the redevelopment and refurbishment of cities and buildings. These urban conglomerations were built in a hurry without thought for valid technical criteria; thus, recycling their waste aggregates during the refurbishment process is a rational choice that has a good chance of succeeding.

The third source of aggregates is better organized and provides the Jordanian market with imported international products. Problems associated with this option relate to costs and the fact that that the Jordanian building sector is an informal one: most building operations are managed by private individuals, posing serious problems for diffusion in the near future, issues, discussed before, highlight the necessity of alternative methods to combine available materials using modern solutions and new easy application techniques result the best way to improve green and sustainable choices' diffusion.

\subsection{Natural techniques for the energy management of buildings}

Previous research has demonstrated the validity of these 
applications. In our case, the question was how to apply them to affordable green housing. The use of passive architecture and natural acclimatization presents a potential solution, depending as it does on designs that respect climatic conditions. Natural techniques can be easily applied because are based on the role of architects and engineers to study and simulate different solutions rather than the consumption of physical resources.

These solutions apply natural theories and are divided into two categories. The first applies the principles of passive architecture, focusing on the architectural design of a building and its configuration, and the second focuses on the proprieties of materials. While the first approach enjoys extensive related research, the second can be defined as a new discipline. When dealing with materials and their proprieties, deeper scientific knowledge is required.

Solutions applying natural theories, adopted to provide affordable techniques for sustainable green building renovations, could benefit of the advanced properties of materials, such as the use of nanotechnology, produced in advanced laboratories [22]. For example, the use microfibers or new insulation materials could be employed maintaining low costs.

In very hot regions, where the problem is how to protect buildings from the sun and create comfortable internal spaces, special types of insulation are needed that not only cause heat transfer by absorption, but also transform the unwanted heat into other forms of energy. This operation is made possible by using heat to change the compression of the insulating material. We noted that compression is a function of temperature and can be expressed as such. By increasing compression, the unwanted heat produces physical work in an unrepeatable way, thus, the work produced cannot be re-transformed into heat. Another method is to use the unwanted heat to change the internal state of the insulation material, for example, from solid to flexible.

\subsection{Micro-applications of alternative energy collection}

The micro-application collection of alternative energy, converted in electric energy, to support home automation uses a centralized network where consumption is managed to provide comfort, minimizing the waste of energy. Other, vital part where energy is managed separately to provide home automation. Home automation separates the complex levels of home networks [23]. Micro-application appliances aim to provide comfort by distinguishing end-user services and managing comfort by employing the electric power produced by micro-cells.

Advanced research into solar energy collection, which has created slim solar cells with reduced dimensions, has opened alternative possibilities for different applications. Many research centers and international societies have focused on reducing cells' surface areas; thus, the possibility of employing solar micro-applications has increased, permitting us to formulate a hypothesis about their development.

An example that supports the argument made in this paper is the use of a water collection system developed by Warka Water [24]. This project began in response to the shortage of potable water in certain regions and provided simple technology for collecting water from the humidity in the air. The importance of this work was not in the quantity of water collected, but in the potential to produce potable water by a sustainable method, reducing health problems in these areas.
The devices can be built by local people with local materials, the cited method (Warka Water) presents a model for capillary collection, it demonstrates that simplified methods could be useful and considered advanced technology.

Another example of the efficiency of micro-collection is the use of micro-turbines to collect wind energy, replacing traditional turbines and enabling the production of energy from low-velocity winds. These micro-turbines produce less noise pollution than traditional turbines but have the same efficiency. Advanced studies and research regarding wind collection technology arrived at the conclusion that it could be maximized by the development of systems that use lowvelocity wind, and this could be obtained in principal way-by replacing the classic turbines with several micro-turbines, as in exemplified by the Wind Tree [25]. The Wind Tree maximizes the benefits of minimal wind flows by locating many micro-turbines, together, on a single installation. The energy collected by the micro-turbines is combined, creating a single power source that can supply significant voltage.

The innovative aspect of our research limits its relevant literature review, but there is supporting evidence from experiments, and the limitation encourages us to develop new theories and concepts. This paper focuses and studies methodologies that simplify alternative energy (solar and wind energy) collection methods to be used in buildings.

The proposed micro-application technology is based on the concept of the micro-collection of energy and on the simplification of its energy-consuming use (principally for heating, lighting, and mechanical ventilation). The proposed technology uses a simple collection-consumption process separate from the main domestic electrical network. The micro-collection of solar or wind energy uses simple devices that work on low flows of energy, based of the total output of the mini-network's collection.

The direct collection of energy permits the energy to be employed for primary needs, such as heating, lighting, and mechanical ventilation and managed, simply and completely, by the users. Thus, the use of simplified technology could help users to satisfy specific needs, increasing comfort and quality of life, previous research into alternative and innovative energy sources has demonstrated their potential and validity on all levels [26].

This paper focus on the potentiality of micro-application collection methods for generating alternative energy and aims to modify energy efficiency in buildings. Small power devices, such as independent solar panels or miniature wind turbines, increase alternative energy use. The high efficiency of such a system can meet up to $50 \%$ of the electricity demand of buildings, which generally have high cooling, heating, and lighting demands.

We cannot consider this consumption as an independent factor, which makes it difficult to understand the underlying changes that affect energy consumption, because there are many forms and types of heating systems used in underdeveloped countries that do not use conventional, alternative, or renewable energy forms, but informal fuels which have a disastrous impact on the environment and public health, as result of alternative energy simplifying is the reduction of negative impacts on the environment and public health. In addition, publicizing comprehensive building energy information will make it easier to plan future energy policies, producing more accurate and efficient analyses. The increasing energy consumption and emissions in developing countries due to the built environment make energy efficiency 
strategies a priority when formulating energy policies.

Developing new, low consumption building techniques and producing innovative applications are crucial requirements. An exponential upward trend in building energy consumption during the coming years, due to the expansion of the urban built area caused by political crises and internal migration in Jordan and globally will result in environmental exhaustion. Enhancing private initiatives to implement solar energy collection using micro applications promotes energy efficiency and raises awareness that the rational use of energy will be essential in making a sustainable future possible.

\section{CONCLUSIONS}

In this paper, we introduced new variables as Sustainable Parametric Potentiality (SPP) and Sustainable Design Parameters (SDP) that could contribute on the diffusion alternative energy and affordable green housing, suggesting a framework of possible variables that play a crucial role, dealing with green affordability issues, producing guidelines that can be adapted easily and thus widely diffused. Particularly in underdeveloped regions with limited access to advanced technology, green and sustainable concepts can provide solutions that permit simple technical applications, useable with the available resources and local knowledge. Our future research will focus on experimentations and laboratory tests aiming to produce executive affordable and green methods to be employed in our reality.

\section{REFERENCES}

[1] Mercer, T., Bentkowska Tuan, N., Radford, A. (2007). What is affordable green housing? Analysis of a competition. Journal of Green Building, 2(1): 130-142. https://doi.org/10.3992/jgb.2.1.130

[2] Smit, A.M., du Toit, F. (2015). Investigating the financial benefits of green buildings. Environmental Economics, $6(3)$ :

61-71. https://businessperspectives.org/journals/author/anet-msmit

[3] Miah, M., Omar, A. (2012). Technology advancement in developing countries during digital age. International Journal of Science and Applied Information Technology, 1(1): $\quad 30-38$. https://www.semanticscholar.org/paper/TechnologyAdvancement-in-developing-countries-Age-MiahOmar/22b752250e726faefd35c64d8836328533bc4c42

[4] Asadi, S., Farrokhi, M. (2015). The challenges of sustainable development and architecture. International Journal of Science, Technology and Society, 3(2): 11-17. https://doi.org/10.11648/j.ijsts.s.2015030201.13

[5] Aldeek, Z. (2017). The evolution of the city of Irbid from a small centre into a Metropolis. 5th Annual International Conference on Architecture and Civil, Engineering, Singapore. 394X_ACE17.79

[6] Lukez, P. (2007). Suburban Transformations. Princeton Architectural Press. New York.

[7] Vermesan, V., Flueckiger, U.P. (2016). Intelligent, parametrically sustainable architectural design. The 6 International Conference on Harmonisation between Architecture and Nature (ARC 2016), 161: 93-105.
https://doi.org/10.2495/ARC160091

[8] Vitruvius, M. (1960). The Ten Books on Architecture. Dover Publications. New York.

[9] Fathy H. (1973). Architecture for Poor. University of Chicago Press. Chicago.

[10] Taleb, H.M. (2014). Using passive cooling strategies to improve thermal performance and reduce energy consumption of residential buildings in U.A.E. buildings. Frontiers of Architectural Research, 3(2): 154-165. https://doi.org/10.1016/j.foar.2014.01.002

[11] Almatarneh, R.T. (2013). Sustainability lessons learnt from traditional architecture: a case study of the old city of As-Salt, Jordan. IOSR Journal of Environmental Science, Toxicology and Food Technology (IOSRJESTFT), 5(3): 100-109.

[12] Pe'rez-Lombard, L., Ortiz, J., Pout, C. (2008). A review on buildings energy consumption information. Energy and Buildings, 40: 394-398. https://doi.org/10.1016/j.enbuild.2007.03.007

[13] Xie, X., Gou, Z. (2017). Building performance simulation as an early intervention or late verification in architectural design: Same performance outcome but different design solutions. Journal of Green Building, 12(1): 45-61. https://doi.org/10.3992/1552-6100.12.1.45

[14] Olgyay, V. (1981). Progettare con il clima. Design with Climate, Franco Muzzio, C. (Eds.). Padua Italy.

[15] Fathy, H. (1986). Natural Energy and Vernacular Architecture: Principles and Examples with Reference to Hot Arid Climates. University of Chicago Press. Chicago.

[16] Alzoubi, H., Malkawi, A.T. (2019). A comparative study for the traditional and modern houses in terms of thermal comfort and energy consumption in Umm Qais City, Jordan. Journal of Ecological Engineering, 20(5): 14-22. https://doi.org/10.12911/22998993/105324

[17] Tathagat, D., Ramesh, D. (2015). Role of green buildings in sustainable construction-need, challenges and scope in the Indian Scenario. IOSR Journal of Mechanical and Civil Engineering (IOSR-JMCE), 12(2): 1-9. http://www.iosrjournals.org/iosr-jmce/papers/vol12issue2/Version-2/A012220109.pdf.

[18] Hubers, H. (2012) Collaborative design of parametric sustainable architecture. Journal of Civil Engineering and Architecture, 6(7): 812-821. https://doi.org/10.17265/1934-7359/2012.07.004

[19] Khoury, H.N. (2014). Importance of clay minerals in Jordan case study: Volkonskoite as a sink for hazardous elements of a high $\mathrm{pH}$ plume. JJEES, Jordan Journal of Earth and Environmental Sciences, 6(3): 1-10. http://jjees.hu.edu.jo/files/Vol6SP3/Vol6SP3_HQ_P110.pdf.

[20] Boulemtafes-Boukadoum, A., Benzaoui, A. (2011). Energy and exergy analysis of solar drying process of mint. Energy Procedia, 6: 583-591. https://doi.org/doi:10.1016/j.egypro.2011.05.067

[21] Aldeek, Z. (2016). Technology and construction techniques' development in the Jordanian building sector. Research Journal of Applied Sciences, Engineering and Technology, 13(8): 675-681. http://dx.doi.org/10.19026/rjaset.13.3053

[22] Joumaa, H., Ploix, S., Abras, S., De Oliveira, G. (2011). A MAS integrated into Home Automation system, for the resolution of power management problem in smart homes. Energy Procedia, 6: 786-794. https://doi.org/10.1016/j.egypro.2011.05.089 
[23] Kazem, H.A. (2011). Renewable energy in Oman: Status and future prospects. Renewable and Sustainable Energy Reviews. 15(8): https://doi.org/10.1016/j.rser.2011.05.015

[24] Occhioni, E. (2014). Warka Water, un progetto italiano per raccogliere l'acqua potabile in Etiopia. https://www.architetturaecosostenibile.it/architettura/pr ogetti/warka-water-acqua-potabile-etiopia-776

[25] Ajayi, O.O., Fagbenle, R.O., Katende, J., Ndambuki, J.M., Omole, D.O., Badejo, A.A. (2014). Wind energy study and energy cost of wind electricity generation in Nigeria: Past and recent results and a case study for South West Nigeria. Energies, 7(12): 8508-8534. https://doi.org/doi:10.3390/en7128508

[26] Menezes, A.C., Cripps, A., Buswell, R.A., Wright, J., Bouchlaghem, D. (2014). Estimating the energy consumption and power demand of small power equipment in office buildings. Energy and Buildings, 75: 99-209. https://doi.org/10.1016/j.enbuild.2014.02.011 